\title{
Sensing Formaldehyde Using Graphene Oxide as Sensing Material
}

\author{
Murthy Chavali ${ }^{1 *}$, Srinivasan $\mathbf{K}^{1}$ and Ren Jang $\mathbf{W u}^{2}$ \\ ${ }^{1}$ Department of Materials Science, MCETRC, India \\ ${ }^{2}$ Department of Applied Chemistry, Providence University, Taiwan
}

*Corresponding author: Murthy Chavali, Department of Materials Science, MCETRC, Tenali, Guntur-522201, Andhra Pradesh, India, Tel: 09642878182; Email: ChavaliM@gmail.com

Submission: 眥 April 01, 2018; Published: 眥 July 26, 2018

\begin{abstract}
Nanomaterials have been widely used in analytical chemistry as chemical sensor and biosensor materials. Graphene, a kind of nanomaterial, has attracted attention increasingly since it was isolated in 2004 showing promising applications in scientific and technological fields owing to its novel properties such as electrical, thermal, and mechanical properties. Graphene and its derivatives including graphene oxide (GO) have attracted everincreasing attention in recent years as a novel class of 2D carbon-based nanomaterials with the promise of a range of applications. G0 has large surface area, excellent conductivity, good chemical stability and easy fabrication; in combination makes GO the paramount materials in the fields of sensors. A graphene oxide (GO) based formaldehyde sensor to detect at room temperature was developed. Graphene oxide was synthesised by modified Hummers method. FT-IR spectra of the graphene oxide revealed these - $\mathrm{OH}$ and - $\mathrm{COOH}$ functional groups were formed on the graphene surface. XRD patterns also showed the formation of graphene oxide material. The p-type semiconductor sensing material of GO was performed and at room working temperature. It was tested as 10 to 50ppm HCHO concentrations for GO, and the sensor response was raised from 2.11 to 6.98. Using Material Studio 4.3 software, the adsorption phenomena were explained to the HCHO sensing property.
\end{abstract}

Keywords: HCHO sensor; Graphene oxide; Formaldehyde; Adsorption; Desorption

\section{Introduction}

Nanomaterials have been widely used in analytical chemistry as chemical sensor and biosensor materials [1] Graphene, a kind of nanomaterial, has attracted attention increasingly since it was isolated [2] It shows promising applications in scientific and technological fields owing to its novel properties such as electrical, thermal, and mechanical properties, graphene and its derivatives; including graphene oxide (GO), have attracted ever-increasing attention in recent years as a novel class of 2-D carbon-based nanomaterials [3] with the promise of a range of applications [4] The oxide of graphene (GO), usually exfoliated from graphite by a mild ultrasonic treatment and bearing lots of electro-active oxygencontaining functional groups and disorder on the basal planes and edges of grapheme [5,6] has been proved to possess overwhelming physical/chemical properties applications in material sciences, [7] energy storage, [8] catalysis, [9] adsorption [10] and electronic devices [11]. GO has large surface area, excellent conductivity, good chemical stability and easy fabrication, in combination makes GO the paramount materials in the fields of Sensors [12,13] and electrocatalysis, [14] which often exhibits electroanalytical performance as excellent as or superior to carbon nanotubes [8]. GO a material of recent interest towards sensors have created a lot of attention due to the fact that it paved the way for solution-based synthesis of graphene sheets and as sensors [15]. Formaldehyde (HCHO) was first reported in 1859 by the Russian chemist Aleks and rButlerov (1828-86) and was conclusively identified in 1869 by August Wilhelm von Hofmann. HCHO, is a known carcinogen found in pathology laboratories [16] due to vapours of formalin solutions (40wt.\% formaldehyde, $12.5 \mathrm{wt} . \%$ methanol and $47.5 \mathrm{wt} . \%$ water) used to preserve tissues, [17] industrial chemical processes, and buildings as a result of condensation polymerization used for building materials, paint and carpets. HCHO is a colourless, strongsmelling gas. It's most significant use in homes as an adhesive resin in pressed wood products (Figure 1).

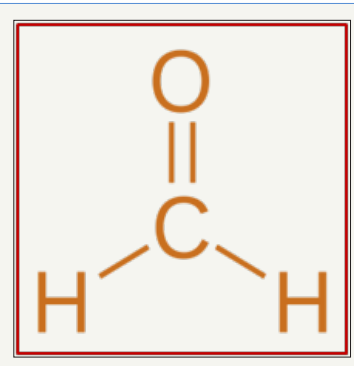

Figure 1 
In particular, $\mathrm{HCHO}$ is considered as a major cause of sick building source [17]. But there are no continuous electronic sensors available for HCHO gas detection; [18] the demand for accurate and devoted sensors to provide precise process control in manufacturing processes, and also to monitor and control environmental pollution, have accelerated the development of new sensing materials and sensor technology in the last decade. Formaldehyde is a naturallyoccurring organic compound with the formula $\mathrm{CH}_{2} \mathrm{O}$. It is the simplest aldehyde and is also known by its systematic name methanal. The common name of this substance comes from its similarity and relation to formic acid. The hazardous formaldehyde levels in air are mandated on a "long-term exposure" basis e.g., averaged over 1-2-week period [16]. Most indoor air pollution is caused by the sources within like storage of adhesives, carpeting, copy machines, manufactured wood products, cleaning agents and pesticides may emit volatile organic compounds (VOCs), including HCHO. Formaldehyde is an important precursor to many other materials and chemical compounds. Its widespread use, toxicity, and volatility, HCHO poses a significant danger to human health [18] The US National Toxicology Program (UNTP) in 2011 described formaldehyde as a human carcinogen [19]. HCHO was declared as a toxic substance by the 1999 Canadian Environmental Protection Act [20]. Formaldehyde is more complicated than many simple carbon compounds in that it adopts several different forms.

As a gas, formaldehyde is colourless and has a characteristic pungent, irritating odour. Upon condensation, the gas converts to various other forms of formaldehyde (with different chemical formulas) that are of more practical value. One important derivative is the cyclic trimer metaformaldehyde or 1,3,5-trioxane with the formula $\left(\mathrm{CH}_{2} \mathrm{O}\right)_{3}$. There is also a linear polymer called paraformaldehyde. Paraformaldehyde is a common form of formaldehyde for industrial applications. When dissolved in water, formaldehyde also forms a hydrate, methanediol, with the formula $\mathrm{H}_{2} \mathrm{C}(\mathrm{OH})_{2}$. This compound also exists in equilibrium with various oligomers (short polymers), depending on the concentration and temperature. Used heavily in Industrial applications, like disinfectant and biocide, tissue fixative and embalming agent, in drug testing and photography etc. Here in this article, we report the fabrication and characterization of sensors based on graphene oxide powder. Graphene oxide is a chemically modified grapheme [21] containing oxygen functional groups such as epoxides, alcohols, and carboxylic acids, [22] and chemical analysis shows the carbon to oxygen ratio to be approximately three to one [23]. Many semiconductor type materials that have been studied for HCHO sensing, include $\mathrm{NiO}$ [16] $\mathrm{Au}-\mathrm{ZnO} / \mathrm{ZnSnO}_{3}$ [24] $\mathrm{ZnO}$ [25] and $\mathrm{Ag}-\mathrm{In}_{2} \mathrm{O}_{3}$ [26]. Above materials are commonly used to detect $\mathrm{HCHO}$ gas at elevated temperatures $\left(>200^{\circ} \mathrm{C}\right)$. A need is to create novel materials for $\mathrm{HCHO}$ sensor at lower working temperature for the reason of saving power and easily portable. Substantially, room temperature operable sensors were found rarely. Here we show this GO material readily detects formaldehyde (HCHO) in the partsper-million ( $\mathrm{ppm})$ range at room temperature.

\section{Experimental Details \\ Materials}

All the chemicals used in this study were of analytical reagent grade (AR) (purity $>99 \%$ ), purchased from Sigma-Aldrich Co., Inc., USA unless otherwise mentioned. Graphite fine powder extra pure (104206), Molar mass 12.01g/mol (CAS number: 7782-42-5) with a particle size $(<50 \mu \mathrm{m}) \geq 99.5 \%$ was obtained from Merck KGaA, Darmstadt, Germany. All the chemicals were used as received. Water was distilled and de-ionized (DI) using a Milli-Q water purification system (Millipore Corp.).

\section{Preparation of sensing material}

GO was synthesised by oxidation of graphite powder using the modified Hummer's method which results in a brownish colloidal suspension [27]. The expandable graphite powders (2g) were stirred in $98 \%$ Conc. $\mathrm{H}_{2} \mathrm{SO}_{4}(35 \mathrm{ml})$ for $2 \mathrm{~h} . \mathrm{KMnO}_{4}(6 \mathrm{~g})$ was gradually added to the above solution while keeping the temperature less than $20{ }^{\circ} \mathrm{C}$. The mixture was then stirred at 35 ${ }^{\circ} \mathrm{C}$ for $2 \mathrm{~h}$. The resulting solution was diluted by adding $90 \mathrm{ml}$ of water under constant stirring and a dark brown suspension was obtained. The suspension was further treated by adding $30 \% \mathrm{H}_{2} \mathrm{O}_{2}$ solution $(10 \mathrm{ml})$ and $100 \mathrm{ml}$ of distilled water. The resulting graphite oxide suspension was washed by repeated centrifugation, first with $5 \% \mathrm{HCl}$ aqueous solution for several times and then with distilled water until the $\mathrm{pH}$ of the solution becomes neutral. The GO material was obtained by adding $180 \mathrm{ml}$ of water to the resulting precipitate and thoroughly sonicated to attain a uniform suspension of GO.

\section{Sensor head fabrication and sensor response to $\mathrm{HCHO}$ gas}

Optimised sensing material (GO) was made into a paste by mixing $0.1 \mathrm{~g}$ with an appropriate organic binder. Then, this mixture was spread on $\mathrm{Al}_{2} \mathrm{O}_{3}$ substrate $(4.0 \mathrm{~mm} \times 2.5 \mathrm{~mm})$ with interdigitatedcomb-like gold electrodes and calcined in air at 300 ${ }^{\circ} \mathrm{C}$. The temperature of the sensor device was controlled at $25 \pm 3$ ${ }^{\circ} \mathrm{C}$, and the relative humidity was $60 \pm 15 \mathrm{RH} \%$. The sensor system comprises an HCHO sensing chamber and associated with a static system was set up in Figure 2a. Based on the calculation of ideal gas equation, the concentration of $\mathrm{HCHO}$ gas can be determined by injection appropriate amount of liquid HCHO solution in liquid sample inlet. A heater was used to heat the HCHO sample into vapour and the vapour mixed in the system by a fan. The system can create a set of concentrations in the range of 10 to $50 \mathrm{ppm}$. The sensor response (S) was defined as $\mathrm{S}=\mathrm{R}_{\mathrm{HCHO}} / \mathrm{R}_{\text {Air }}$ and the temperature of the sensor device was controlled at $25 \pm 3{ }^{\circ} \mathrm{C}$. Sensor signals from the sensor head were converted to resistance using a simple circuit in circuit board via a computer for data acquisition and processing.

\section{Instrumental techniques (UV/Vis, FT-IR, XRD) and theoretical analysis}

The obtained GO sensing sample was characterised by using UV/ Vis spectroscopy. The UV/Vis spectrometer used here was SINCO, SUV-2100 series. Light sources for the UV-Vis were deuterium 
and tungsten, halogen lamps, respectively, and the wavelengths scanned between 200 to $800 \mathrm{~nm}$. Fourier transform infrared (FTIR) spectra of the graphene oxide were done with Alpha-T FT-IR (Bruker Optics, Germany) equipped with a deuterated L-alanine doped triglycene sulphate (DLaTGS) detector. Transparent film material was measured directly over ZnSe ATR without any sample preparation. The spectrum was collected with 64 scans at room temperature and at a resolution of $4 \mathrm{~cm}^{-1}$. The sensing materials were characterised by X-ray diffractometer (XRD); Shimadzu XRD 6000; X-ray Tube-Cu (1.54060 Å). Various samples were identified by $2^{\circ}$ angles, and the particle planes were estimated (XRD voltage: $40.0 \mathrm{keV}$ and current: $30.0 \mathrm{~mA}$ ). The scanning $2^{\circ}$ range was between $10^{\circ}-70^{\circ}$, at a scanning rate of $4^{\circ} / \mathrm{min}$. A series of molecular dynamics/simulations calculated the bonding energy for HCHO molecule adsorption into the graphene oxide surface using Material Studio software, Version 4.3 (Accelrys Software Inc., USA, http://www.accelrys.com/products/msstudio/). By applying the discovery method of the software, the parameters were chosen to minimise the system energy, and the force field was chosen as the compass item. The calculated energy could be estimated, and the adsorption and desorption interaction phenomena of $\mathrm{HCHO}$ molecule and GO could, therefore, be obtained.

\section{Result and Discussion}

\section{UV, XRD and FT-IR characterization of GO}

Figure $2 \mathrm{~b}$ shows that UV/Visible absorption spectrum of grapheme oxide sample prepared using Hummers method. A peak at $232 \mathrm{~nm}$, which is due to $\pi$ to $\pi *$ transition of the functional groups $\mathrm{C}=\mathrm{O}$ and $\mathrm{C}=\mathrm{C}$ of $\mathrm{GO}$, this experimental spectra data is matched with published results [18]. Figure 2c shows the XRD pattern of graphene oxide synthesised using Hummers method. The (002) peak of graphene oxide having reduced intensity and highly broaden, which indicates that the Graphene oxide composed of mainly single carbon sheets and having a high density of pores [28]. No other additional peaks were observed, it confirms that the sample has purity [28]. Figure $2 \mathrm{~d}$ shows the spectrum of graphene oxide, the peak at $1707 \mathrm{~cm}^{-1}$ is characteristic of the $\mathrm{C}=0$ stretch of the carboxylic group on the graphene oxide and also $1579 \mathrm{~cm}$ ${ }^{1}$ is characteristic of the $\mathrm{C}=0$ stretch. The peak at $1396 \mathrm{~cm}^{-1}$ is characteristic of the $\mathrm{C}$-C stretch of aromatic compound. The peak at $1010 \mathrm{~cm}^{-1}$ is characteristic of the C-O stretch. The peak at $3162 \mathrm{~cm}$ ${ }^{1}$ is characteristic of $\mathrm{O}-\mathrm{H}$ high concentration broad peak.19. Above results reveal the existence functional groups of $-\mathrm{OH}$ and $-\mathrm{COOH}$ on GO surface.

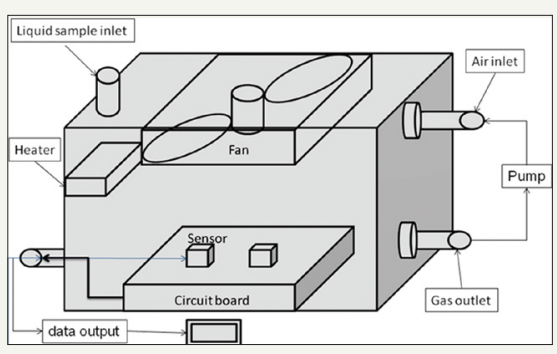

(a)

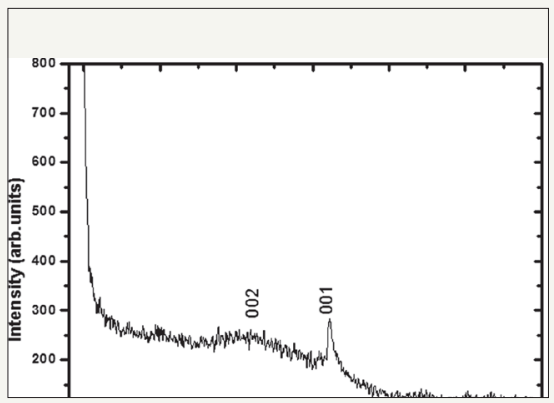

(c)

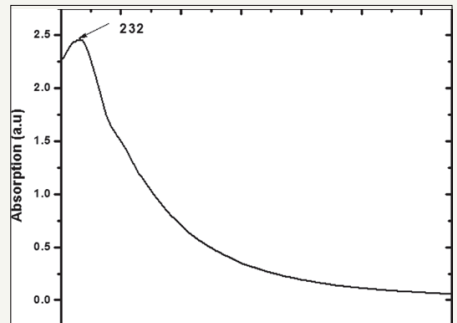

(b)

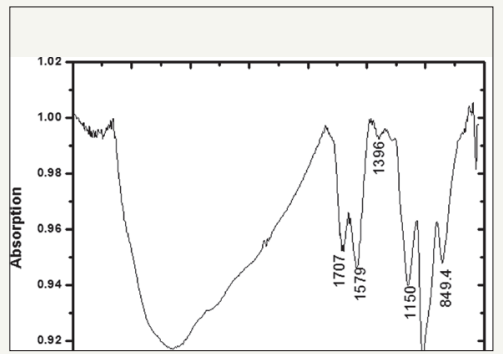

(d)

Figure 2:

2a: Sensing setup;

2b: $\mathrm{UV} / \mathrm{Vis}$ spectrum of GO;

2c: XRD spectrum of GO;

2d: FT-IR spectrum of GO.

\section{Sensing curve of HCHO gas and short-term repeatability}

Figure $3 \mathrm{a}$ shows the response curve of the sensing material graphene oxide at room temperature $\left(25 \pm 3^{\circ} \mathrm{C}\right)$ exposed to $50 \mathrm{ppm}$ formaldehyde at room temperature. The output resistance signal depicts the drop from the resistance $\mathrm{R}_{\text {Air }}$ to the equilibrium value $\mathrm{R}_{\mathrm{HCHо}}$ that occurs when the formaldehyde gas enters the test chamber and its purging brings back to the background value indicating the absence of alcohol. Response time $t_{90}$ (time needed 
to obtain a result equal to $90 \%$ of the equilibrium signal) and the recovery time $t_{R}$ (time needed to bring the signal back to $90 \%$ of the HCHO background signal) both were 398s and 587s. The sensor response for 50ppm of $\mathrm{HCHO}$ was 6.98. A decrease in the output resistance when the formaldehyde contacts the grapheme oxide surface implies a decrease in sensor resistance, indicating that the graphene oxide is $p$-type semiconductor formaldehyde sensor.

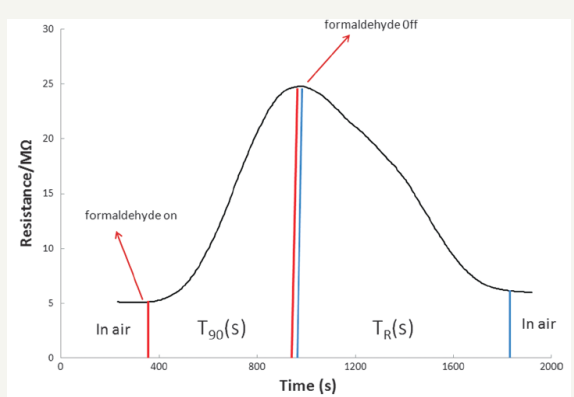

(a)

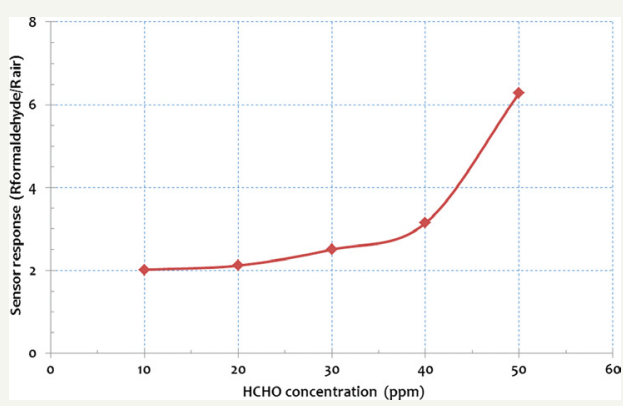

(c)

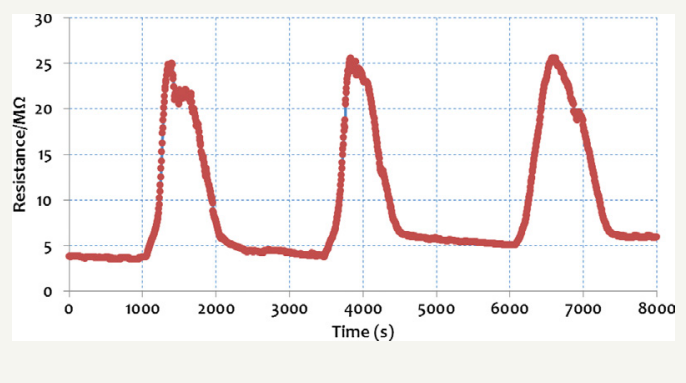

(b)

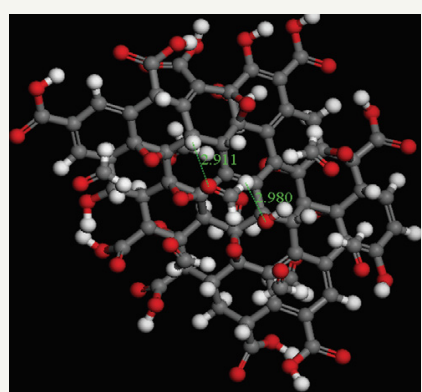

(d)

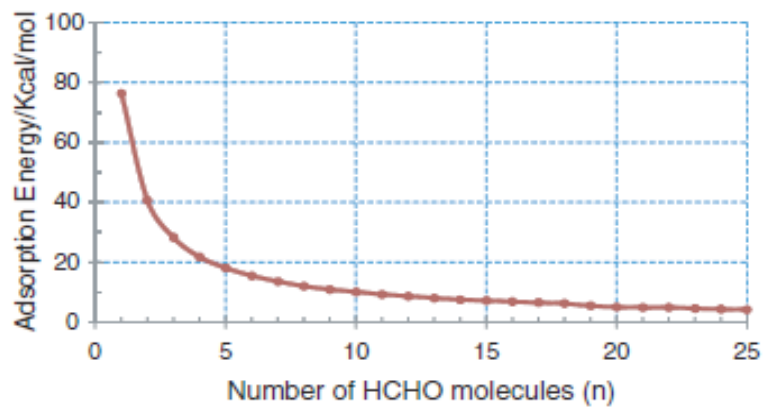

(e)

\section{Figure 3:}

3a: The response curve of GO towards 50ppm HCHO;

3b: Response curves of various samples of GO towards 50ppm HCHO;

3c: Sensor responses Vs 10 to 50ppm HCHO concentration with GO;

3d: Side view of $\mathrm{HCHO}$ adsorption on $\mathrm{GO}$ and the $\mathrm{HCHO}$ adsorption number is 10. White ball represents 'H2' atom; black ball represents ' $\mathrm{C}$ ' atom; red ball represents 'O' atom;

3e: $\mathrm{HCHO}$ adsorption energy Vs adsorption number of HCHO on GO surface.

Table 1 gives the sensing properties/data of graphene oxide to $50 \mathrm{ppm}$ formaldehyde. Graphene oxide sensors also had sensor responses $\left(\mathrm{S}=\mathrm{R}_{\mathrm{HCHO}} / \mathrm{R}_{\mathrm{Air}}=6.98\right)$, middle response times $\left(\mathrm{t}_{90}=398 \mathrm{~s}\right)$ and recovery times $\left(t_{R}=587 \mathrm{~s}\right)$. Figure $3 \mathrm{~b}$ presents the series response curves versus time of graphene oxide to 50ppm HCHO. It showed the three peaks are quite the same, so the short-term stability of GO to detect HCHO is good. But the baseline of the curve was increasing with additional time; it could be some force between the HCHO and GO surface.

\section{Sensing properties Vs various HCHO concentrations}

Figure $3 \mathrm{c}$ shows sensor responses versus 10 to $50 \mathrm{ppm}$ formaldehyde concentration of graphene oxide. Obviously, sensor response increased with increasing formaldehyde concentration. 
The responses of the sensor were 2.11 and $6.98\left(\mathrm{~S}=\mathrm{R}_{\mathrm{HCHO}} / \mathrm{R}_{\mathrm{Air}}\right)$ to the concentrations of 10 and $50 \mathrm{ppm}$, respectively. Table 1 revealed that the response and recovery times were decreasing by increasing the formaldehyde concentration from 10 to $50 \mathrm{ppm}$ in graphene oxide. It showed on $10 \mathrm{ppm}$ formaldehyde the response and recovery times were 742 and 1200 s, respectively, and to $50 \mathrm{ppm}$ formaldehyde, the response and recovery times were decreasing as 398 and 587s, respectively.

Table 1: Sensor response, $t_{90}(s)$ and $t_{R}(s)$ values are 10 to 50 ppm HCHO concentration of GO.

\begin{tabular}{|c|c|c|c|}
\hline HCHO Concentration (ppm) & $t_{90}(s)$ & $t_{R}(s)$ & $\begin{array}{c}\text { Sensor Response } \\
\left(\mathbf{R}_{\mathrm{HCHO}} / \mathbf{R}_{\mathrm{Air}}\right)\end{array}$ \\
\hline 10 & 742 & 1200 & 2.11 \\
\hline 20 & 720 & 1197 & 2.12 \\
\hline 30 & 707 & 1040 & 2.51 \\
\hline 40 & 590 & 909 & 3.14 \\
\hline 50 & 398 & 587 & 6.98 \\
\hline
\end{tabular}

\section{Simulation of HCHO adsorption on GO surface}

We assume the sensing behaviour is related to the reversible adsorption and desorption process between HCHO molecules and GO vacancy surface site (*), as described in Eq. (1).

$$
\mathrm{HCHO}+* \leftrightarrow H C H O-*
$$

From the analysis of UV/Vis, XRD and FT-IR spectra in Section 3.1, the existence functional groups of $-\mathrm{OH}$ and $-\mathrm{COOH}$ on $\mathrm{GO}$ surface in the simulation model. By using the computation MS 4.3 adsorption method, the energy of the formaldehyde molecule for graphene oxide material surface adsorption was measured as an exothermic reaction. Figure $3 \mathrm{~d}$ revealed the side view of formaldehyde adsorption on graphene oxide, and the formaldehyde adsorption number is 10 . The adsorption bond lengths of $\mathrm{O}-\mathrm{H}$ (O atom is from $\mathrm{HCHO}$ and $\mathrm{H}$ atom is from graphene oxide) were calculated as $2.91 \times 10^{-8}$ to $2.98 \times 10^{-8} \mathrm{~cm}$ from Figure $3 \mathrm{~d}$. The bond length belongs to the normal hydrogen bond. In Figure 3e revealed that one formaldehyde molecule of adsorption heat was $-76.4 \mathrm{kcal} / \mathrm{mol}$, and this value was close to the chemical adsorption $(-40 \mathrm{kcal} / \mathrm{mol})$. (Figure 3e), the molecular adsorption exothermic value (-kcal/mol) fell while the molecular number of the formaldehyde molecule rose. Therefore, some of the HCHO molecules are irreversibly adsorbed on the GO surface and the background curve with an increase in time (Figure $3 \mathrm{~b}$ ). When the formaldehyde adsorption number was increased to 10 , the molecular adsorption exothermic value was fallen to the value as $-10.1 \mathrm{kcal} / \mathrm{mol}$. This value was close to the normal hydrogen bond $(-10 \mathrm{kcal} / \mathrm{mol})$. When the formaldehyde adsorption number was increased to 26 , the molecular adsorption exothermic value fell to $-3.98 \mathrm{kcal} / \mathrm{mol}$. This value was close to the weak hydrogen bond $(-4 \mathrm{kcal} / \mathrm{mol})$. The bond energy is larger than Van der Waals force $(-1 \mathrm{kcal} / \mathrm{mol})$. However, under the actual state, many $\mathrm{HCHO}$ molecules adsorption and the adsorptive capacity is far bigger than 26 . Therefore, under the actual state, the formaldehyde molecule was close to weak hydrogen bond adsorption on the material surface. Therefore, the middle response times $\left(t_{90}=398 \mathrm{~s}\right)$ and recovery times $\left(t_{R}=587 \mathrm{~s}\right)$ appeared in the sensing curve.

Above simulation results can explain the sensing data of section 3.3. For $10 \mathrm{ppm}$ HCHO gas input, the response and recovery times were 742 and 1200s, respectively. Increasing formaldehyde concentration to $50 \mathrm{ppm}$, the response and recovery times were decreasing as 398 and 587s, respectively in Table 1. While HCHO concentration is increased, response and recovery times are decreased. The reason is if the HCHO concentration is low, most of the HCHO molecules with strong chemical adsorption or normal hydrogen bond adsorption. So the HCHO molecule is not easily desorbed and adsorbed, therefore the response and recovery time could be larger in low concentration HCHO.

\section{Conclusion}

The present investigation is a useful contribution in the field of vapour sensors. In this study, promising, meaningful findings and interesting results were found with regard to the GO as a sensor for the detection of volatile organic compounds, particularly, Formaldehyde. In summary, GO synthesised by modified Hummer's method. The gas sensing results showed that the sensor had promising potential for formaldehyde. Typically at the room, working temperature, the recovery time $t_{R}$ (time needed to bring the signal back to $90 \%$ of the background signal) both were 393s and $584 \mathrm{~s}$. The responses of the sensor were 2.11 and $6.98\left(\mathrm{~S}=\mathrm{R}_{\mathrm{HCHO}} / \mathrm{R}_{\mathrm{Air}}\right)$ to the concentrations of 10 and $50 \mathrm{ppm}$, respectively. Nevertheless, there is a scope for additional progress and development for further avenues and steps ahead,

1. Using GO as such or experimenting with Graphene in studying the behaviour of structural and electrical properties in the presence of vapours can help in revealing the sensing process and mechanism so as to develop a definite model predicting the performance.

2. Fabrication of a robust sensor needs to be taken up.

Development of an intelligent sensor for ultra-trace levels by an integrating a number of sensors in arrays is an exciting field for extension of present research and efforts were in that direction in our laboratory.

\section{References}

1. Valdés MG, González ACV, Calzón JAG, García MED (2009) Analytical nanotechnology for food analysis. Microchimica Acta 166(1-2): 1-19.

2. Novoselov KS, Geim AK, Morozov SV, Jiang D, Zhang Y, et al. (2004) Electric field effect in atomically thin carbon films. Science 306(5696): 666-669.

3. Meyer JC, Geim AK, Katsnelson MI, Novoselov KS, Obergfell D, et al. (2007) On the roughness of single- and bi-layer graphene membranes. Solid State Commun 143: 101-109.

4. Zhou XZ, Huang X, Qi XY, Wu SX, Xue C, et al. (2009) In situ synthesis of metal nanoparticles on single-layer graphene oxide and reduced graphene oxide surfaces. J Phys Chem C 113(25): 10842-10846. 
5. Gan T, Hu C, Chen Z, Hu S (2010) Fabrication and application of a novel plant hormone sensor for the determination of methyl jasmonate based on self-assembling of phosphotungstic acid-graphene oxide nanohybrid on graphite electrode. Sens Actuators B Chem 151(1): 8-14.

6. Stankovich S, Dikin DA, Dommett GHB, Kohlhaas KM, Zimney EJ, et al. (2006) Graphene-based composite materials. Nature 442(7100): 282 286.

7. Mattevi C, Eda G, Agnoli S, Miller S, Mkhoyan KA, et al. (2009) Evolution of electrical, chemical, and structural properties of transparent and conducting chemically derived graphene thin films. Adv Funct Mater 19(16): 2577-2583.

8. Bourlinos AB, Gournis D, Petridis D, Szabo T, Szeri A, et al. (2003) Graphite oxide: chemical reduction to graphite and surface modification with primary aliphatic amines and amino acids. Langmuir 19(15): 60506055.

9. Li J, Vaisman L, Marom G, Kim JK (2007) Br treated graphite nanoplatelets for improved electrical conductivity of polymer composites. Carbon 45(4): 744-750.

10. Seredych M, Pietrzak R, Bandosz TJ (2007) Role of graphite oxide (GO) and polyaniline (PANI) in $\mathrm{NO}_{2}$ reduction on GO-PANI composites. Ind Eng Chem Res 46(21): 6925-6935.

11. Joung D, Chunder A, Zhai L, Khondaker SI (2010) High yield fabrication of chemically reduced graphene oxide field effect transistors by dielectrophoresis. Nanotechnology 21(16): 165202.

12. Zuo XL, He SJ, Li D, Peng C, Huang Q et al. (2010) Graphene oxidefacilitated electron transfer of metalloproteins at electrode surfaces. Langmuir 26(3): 1936-1939.

13. Liu Y, Yu DS, Zeng CZ, Miao C, Dai LM (2010) Biocompatible graphene oxide-based glucose biosensors. Langmuir 26(9): 6158-6160.

14. Wang Y, Li YM, Tang LH, Liu J, Li JH (2009) Application of graphenemodified electrode for selective detection of dopamine. Electrochem Commun 11(4): 889-892.

15. Singh V, Joung D, Zhai L, Das S, Khondaker SI, et al. (2011) Graphene based materials: past, present and future. Prog Mater Sci 56(8): 11781271.

16. Dirksen JA, Duval K, Ring TA (2001) NiO thin-film formaldehyde gas sensor. Sens Actuators B: Chem 80(2): 106-115.
17. Kim WJ, Terada N, Nomura T, Takahashi R, Lee SD, et al. (2002) Effect of formaldehyde on the expression of adhesion molecules in nasal microvascular endothelial cells: the role of formaldehyde in the pathogenesis of sick building syndrome. Clin Exp All 32(2): 287-295

18. IARC Working Group on the Evaluation of Carcinogenic Risks to Humans (2006) Formaldehyde, 2-Butoxyethanol and 1-tert-Butoxypropan-2-ol. IARC Monogr Eval Carcinog Risks Hum 88: 1-478.

19. (2006) Formaldehyde (gas) International agency for research on cancer. Report on Carcinogens, (11 ${ }^{\text {th }}$ edn), Lyon, France, pp. 39-325.

20. National Toxicology Program (2011) NTP $12^{\text {th }}$ report on carcinogens. Rep Carcinog 12: iii-499.

21. Potts JR, Dreyer DR, Bielawski CW, Ruoff RS (2011) Graphene-based polymer nanocomposites. Polymer 52(1): 5-25.

22. He H, Klinowski J, Forster M, Lerf A (1998) A new structural model for graphite oxide. Chem Phys Lett 287(1-2): 53-56.

23. Stankovich S, Piner RD, Nguyen ST, Ruoff RS (2006) Synthesis and exfoliation of isocyanate-treated graphene oxide nanoplatelets. Carbon 44(15): 3342-3347.

24. Xu J, Jia X, Lou X, Xi G, Han J, et al. (2007) Selective detection of HCHO gas using mixed oxides of $\mathrm{ZnO} / \mathrm{ZnSnO}_{3}$. Sens Actuators $\mathrm{B}$ : Chem 120(2): 694-699.

25. Chu X, Chen T, Zhang W, Zheng B, Shui H (2009) Investigation on formaldehyde gas sensor with $\mathrm{ZnO}$ thick film prepared through microwave heating method. Sens Actuators B: Chem 142(1): 49-54.

26. Wang J, Zou B, Ruan S, Zhao J, Chen Q, et al. (2009) HCHO sensing properties of Ag-doped $\operatorname{In}_{2} \mathrm{O}_{3}$ nanofibers synthesized by electrospinning. Mater Lett 63(20): 1750-1753.

27. Hirata M, Gotou T, Horiuchi S, Fujiwara M, Ohba M (2004) Thin-film particles of graphite oxide 1: High-yield synthesis and flexibility of the particles. Carbon 42(14): 2929-2937.

28. Zhu Y, Murali S, Stoller MD, Ganesh KJ, Cai W, et al. (2011) Carbon-based supercapacitors produced by activation of graphene. Science 332(6037): 1537-1541.
Creative Commons Attribution 4.0 International License

For possible submissions Click Here
Submit Article

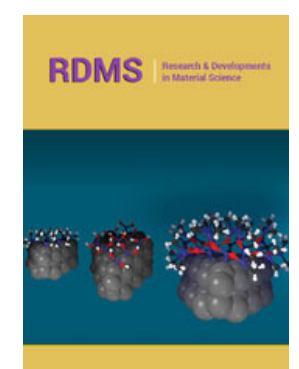

Research \& Development in Material Science

\section{Benefits of Publishing with us}

- High-level peer review and editorial services

- Freely accessible online immediately upon publication

- Authors retain the copyright to their work

- Licensing it under a Creative Commons license

- Visibility through different online platforms 